\title{
NINA RODRIGUES E A PATOLOGIZAÇÃO DO CRIME NO BRASIL
}

\author{
Cristiane Brandão Augusto e Francisco Ortega
}

\section{RESUMO}

ESTE ARTIgo SE DEDICA À ANÁLISE dO MOVIMENTO dE "PATOLOGIZAÇÃO" DO CRIMINOSO POR UMA LEITURA HISTÓRICA DO IMPACTO DO "CIENTIFICISMO CEREBRAL" NA ESFERA CRIMINAL. MAIS PARTICULARMENTE, ATENTA-SE PARA A RECEPCCÃO DAS TEORIAS DE MATRIZ LOMBROSIANA PELA CRIMINOLOGIA BRASILEIRA DO SÉCULO XIX, NA QUAL SE VÊ O MICROCOSMO DO CONFLITO DE INTERESSES DE CLASSES E RAÇAS MEDIADO PELA AUTORIDADE MÉDICA QUE, NA SUA CRENÇA CIENTÍFICA IOU NA SUA FILIAÇÃO IDEOLÓGICA), PROCURAVA ESCLARECER OS LIMITES ENTRE A FALTA MORAL E A LOUCURA - OU OS DOIS (LOUCURA MORAL) COMO DOENCA OU COMO PURA PERVERSIDADE - E PROCURAVA APONTAR PARA OS JUÍZES A FORMA CORRETA (CIENTÍFICA) DE SE SANCIONAR OU DE SE TRATAR A LOUCURA.

\section{PALAVRAS-CHAVE}

Antropologia criminal, Doença mental, Patologização, Nina Rodrigues
NINA RODRIGUES AND THE PATHOLOGIZATION OF CRIME IN BRAZIL

\section{ABSTRACT}

THE CURRENT WORK AIMS AT PERFORMING AN ANALYSIS OF THE CRIMINALS "PATHOLOGIZATION" MOVEMENT BY MEANS OF A HISTORICAL READING OF THE IMPACT OF "BRAIN SCIENTIFICISM" IN THE CRIMINAL SPHERE. MORE PARTICULARLY, THERE IS AN EMPHASIS ON THE RECEPTION OF THE LOMBROSIONISM MATRIX THEORIES IN 19TH-CENTURY BRAZILIAN CRIMINOLOGY, IN WHICH WE CAN SEE THE MICROCOSMS OF CLASSES AND RACES CONFLICTS OF INTERESTS, MEDIATED BY THE MEDICAL AUTHORITY WHO, IN HIS SCIENTIFIC BELIEFS IOR IN HIS IDEOLOGICAL FILIATIONS), LOOKED FOR ILLUMINATE THE LIMITS BETWEEN THE MORAL FAULT AND THE MADNESS - OR THE BOTH (MORAL MADNESS) AS PATHOLOGY OR AS PURE PERVERSITY AND TRIED TO SHOW THE CORRECT FORM (SCIENTIFIC) OF PUNISHING OR TREATING.

\section{KEYWORDS}

CRIMINAL ANTHROPOLOGY, MENTAL ILLNESS,

Pathologization, Nina Rodrigues

\section{INTRODUÇÃO}

O paradigma naturalista da medicina ocidental do século XIX impactou as explicações sobre a conduta humana, alcançando também a conduta delituosa. Ao se desmistificar a igualdade de todos por meio da naturalização das diferenças, reforçaram-se os componentes biológicos causais e, por conseguinte, uma visão mais fisicalista, menos abstrata, foi incorporada nas explicações da ação criminosa, suscitando revisões dos parâmetros da teoria clássica. Leituras médicas sobre o fenômeno do crime, focado na etiologia a partir de dados eminentemente biólogos, formam o conjunto da rede de saber-poder ${ }^{1}$ 
edificada nas instituições médico-jurídicas e multiplicada pelos “cientistas” do Iluminismo e a qual podemos denominar "medicalização do crime" ou, mais especificamente pelas matrizes teóricas da relação crime-doença, denominar de "patologização do crime”.

Por toda a trajetória da cientificidade da medicina e a autoridade atribuída aos médicos na produção de verdades, o paradigma da racionalidade biológica ocupou, historicamente, um espaço privilegiado na fabricação de certezas não limitadas à esfera médica. Uma medicalização da sociedade, então, não se encontra nessa posição privilegiada somente nos dias de hoje e sua estreita relação com a criminologia também não é recente (Serpa Jr., 1998; Rousseau, 1993; Darmon, 1991).

Não se pretende, todavia, afirmar que a medicina é uma entidade dotada de uma essência - e de uma essência negativa -, cuja razão de existir estaria reduzida às conspirações políticas de controle e de poder. É por isso que, apesar do termo "medicalização" ter sido utilizado amplamente pelas ciências sociais com uma conotação crítica à patologização da sociedade e seus desdobramentos, implicando uma censura ao reducionismo, há outras questões envolventes que merecem ser destacadas dessa análise.

Melhor explicando, em que pesem as tradicionais leituras sobre "medicalização/patologização" das últimas décadas, alguns autores vêm alertando para uma utilização desmedida e pouco precisa do termo, bem como para a relevância de se perceber uma relação bidirecional entre a medicina e a sociedade, que aponta para novas valorações nos dias de hoje (Rosenberg, 2006; Rose, 2007). Não se trataria de uma via de mão única, como a manifestação de um saber-poder soberano que submeteria seus súditos e nenhum impacto sofreria. Trata-se, em verdade, de um movimento de ida e volta, que gera ações e que também é gerado por ações dos indivíduos e dos grupos (Rosenberg, 2006). Por exemplo, o processo de incursão da medicina na sociedade, fortemente estabelecido a partir do século XIX, nos permitiu ser o que atualmente somos, e agir, individual ou coletivamente, como agimos: as práticas cotidianas de higiene, dieta, vacinação; metáforas médicas e formas de compreensão dos problemas sociais a partir do organismo; a introdução de terapêuticas para controle e estabilização dos humores, emoções, desejos, etc. (Rose, 2007).

Ademais, é de se convir que o projeto médico de alcançar autoridade para além dos limites de sua competência talvez não integrasse as aspirações de todos os médicos, nem, realmente, tenha se concretizado por completo. Assim, se é possível admitir não ter havido uma patologização de todas as esferas da sociedade, é necessário checar quais categorias médico-positivistas de fato foram incorporadas ao nosso cotidiano e à legislação brasileira.

\section{O CIENTIFICISMO E A ANTROPOLOGIA CRIMINAL BRASILEIRA}

No Brasil o movimento da medicalização se manifestou fortemente no final dos anos 1800. Roque Spencer Maciel de Barros, em seus estudos sobre a "ilustração 
brasileira", considera que a partir de $1870^{2}$ tivemos anos bastante representativos em função de acontecimentos externos (a terceira República francesa e a Guerra Franco-alemã) e internos (fim da Guerra com o Paraguai e fundação do Partido Republicano). Sem deixar de reconhecer as "raízes em passado pouco longínquo", as duas últimas décadas do Império corresponderam ao momento em que "ganham corpo as novas ideias do século - Positivismo, Darwinismo, Materialismo etc. -, a 'reação científica', enfim, para usar de uma expressão empregada por Clóvis Bevilaqua” (Barros, 1986).

O clima de um iluminismo atrasado absorve boa parte de nossos estudiosos que passam a focar na ciência para responder às questões sobre os caminhos a serem trilhados pela literatura, pela política, pelo direito, pela educação e pelo aprimoramento moral. No processo de adequação da mentalidade brasileira ao Positivismo, era preciso, agora, resgatar o "tempo perdido" através da formação intelectual e da cultura. O propósito era atingir os níveis de aprimoramento da "civilização", atingir o "nível do século", desembocando, inevitavelmente, na forma republicana de governo para superar o "atraso cultural" e fazer-nos acompanhar o progresso mais evoluído das sociedades. A consequência inarredável era a laicização do Estado, do Direito, da Medicina, da Educação, enfim, da vida.

Em sentido macro, portanto, a civilização obedeceria a um processo histórico único de evolução, mas o estágio de desenvolvimento de cada sociedade corresponderia à sua fase evolutiva neste processo.

Significava um alto grau evolutivo-social o reconhecimento concreto das liberdades e das igualdades. No caso brasileiro, pleiteava-se ainda a efetivação de direitos básicos através da remodelação ou eliminação de instituições inconciliáveis com as novas pretensões liberais, como era o caso, por exemplo, da escravidão e da vinculação entre Igreja e Estado.

Ao lado do Liberalismo, o Cientificismo angariou seus representantes brasileiros. Mais uma vez, Barros distingue um do outro pelo ponto de partida, se bem que, em geral, o ponto de chegada era o mesmo: o primeiro partia do valor para implementar ações ("a legislação adequada pode transformar o povo”), enquanto o segundo partia do ser, do conhecimento do real, para o dever-ser ("o povo adequado pode transformar a legislação").

De acordo com os valores cientificistas, a "marcha fatal" do universo físico também se verifica no universo humano, pois este pertence ao mesmo mundo daquele, porém em nível mais complexo. Daí porque Barros entende ter o novo cientificismo, o do final do século XIX, uma perspectiva dinâmica, histórica, de desenvolvimento, de evolução, ou seja, "o mundo humano, como objeto de conhecimento, não é mais dado como algo que é, mas como algo que vem a ser” (Barros, 1986). O objeto dinâmico de conhecimento integra a sociologia, a biologia, a psicologia, a criminologia, etc. 
A conduta humana passa a ser apreciada de forma individualizada, contudo, em relação à etapa do progresso da humanidade. Em outras palavras, o comportamento do indivíduo deve ser avaliado na conformidade de suas particularidades biopsicológicas, mas, ao mesmo tempo, os "biologismos" e os "psicologismos" estavam imersos na dinâmica universal da evolução, pelo contributo do Materialismo, Positivismo, ${ }^{3}$ Darwinismo, Spencerismo e Haeckelianismo.

Com efeito, se o Brasil da primeira metade do século XIX estava começando a receber os informes de um cientificismo, na segunda metade daquele mesmo século, o país estava começando a se inscrever num cientificismo positivista e darwinista, pelo qual se proporcionou ultrapassar eficazmente os umbrais da Faculdade de Medicina para se estender a outros campos, como a política, a educação, o direito.

Ao associar o estado individual do nacional com o estágio de desenvolvimento universal, a intelectualidade permitiu a visualização de um papel maior da ciência médica, não circunscrito ao organismo pessoal, mas prescrevendo a terapêutica ao organismo social. Esse movimento de ampliação da intervenção médica é também um registro indireto do objetivo de se elevar a nação brasileira à mesma fase de algumas nações europeias, notadamente a França ou a Alemanha.

De qualquer modo, aqui, a tutela do criminoso também passou a ser disputada pela Justiça e pela Medicina. Os chamados crimes sem razão abriram grandemente a porta para a entrada da psiquiatria na esfera criminal e, à medida que ela foi adentrando, foi diminuindo a importância das medições e da antropometria: "uma das consequências da psiquiatrização crescente do exame médico-legal foi o recuo da antropometria. Dos tempos gloriosos de fins do XIX, quando Lombroso era vivo e a superfície do corpo, sua aparência e suas medidas podiam representar as janelas da alma, quase nada sobrevivia nos anos 1830 e 1840”(Ferla, 2005). Não que elas tenham deixado de perfazer o conteúdo dos exames médico-legais, mas a relevância de outrora não mais se punha.

Antes de 1870, portanto, a intervenção médica no campo criminológico era bem tímida, resguardada aos casos em que era necessário a constatação de que o agente era um louco de todo gênero para efeitos de desculpabilização - constatação reclamada como questão de fato (a evidência da alienação pelo senso comum), por alguns, e questão de direito, por outros (a avaliação técnico-científica não condicionaria a decisão judicial).

A partir da generalização das patologias mentais, com um certo número de "doenças" comportamentais - principalmente, a partir das teorias do atavismo e da degeneração -, a figura do médico-perito se tornou indispensável tanto para proceder ao diagnóstico do louco (fosse o louco moral, o degenerado, o alienado, etc.), como para o tratamento mais humanizado e mais adequado no que tange à resposta penal correta e suficiente para quem realizou o fato definido em lei como crime.

Ademais, com o programa higienista, a medicina social construiu planos de ação preventiva, unindo a "limpeza" dos focos de doença a padrões de comportamento moral, que exigiam a adequação da população ao que teria sido rotulado como puro, 
sadio, saudável. Fugir desses padrões caracterizava infração penal e, no fundo, representava uma certa forma de loucura: o que podia levar alguém a não aderir às normas da sociedade, as quais pretendiam, no final, a sua própria proteção e bem-estar? A classe intelectual dominante tinha dificuldades de compreender a "renúncia racional" aos códigos vigentes por certas camadas sociais e, por conseguinte, as tentativas de responder a tais inquietantes perguntas vinham, geralmente, pela desvinculação dos comportamentos aos valores morais.

Nesse ponto, o Judiciário e a Medicina se aproximavam. As explicações por certa amoralidade comportamental agradavam aos parâmetros com que o Judiciário estava habituado a lidar e, por outro lado, possibilitavam os médicos a definir a (ir)responsabilidade do agente com base em sua "vida pregressa", o histórico de sua existência e ainda de seus parentes. Ao mesmo tempo, a confusa relação entre medicina e direito penal, que tanto favoreceu as publicações da Criminologia Científica ou Positiva, ao ser transplantada para os Asilos de Alienados ou para, depois, os Manicômios Judiciários, transpareceu o obscuro limite entre o tratamento psicopatológico e o tratamento moral ou a ambiguidade entre a instituição da prisão e a instituição do asilo.

Se no texto legal parecia clara a diferença entre os imputáveis e os inimputáveis e, consequentemente, o tipo de reclusão/internação que deveriam receber, bem como o cuidado técnico a ser-lhes dirigido, se médico ou jurídico, no plano concreto, todavia, as práticas institucionais eram dúbias e pouco definidas. Primeiramente, não havia consenso sobre a elasticidade da interpretação da legislação, pois, afinal, qual é o alcance da expressão "louco de todo gênero"? Ou com o Código de 1890, o alcance da expressão "completa privação de sentidos e de inteligência”? Em segundo lugar, exigia-se adequação "moral" ao louco, bem como superação da "patologia" do criminoso. Falava-se em Manicômio ou em seção especial no Hospício para os "loucos-criminosos" e presídios específicos para "reincidentes incorrigíveis", ou seja, de certo modo, a prisão se fez asilo e o asilo se fez prisão, guardando entre si a característica das instituições totais (Goffman, 2008).

Com efeito, a progressiva intervenção da medicina psiquiátrica na justiça vai, aos poucos, incorporando outros comportamentos delituosos em que se põe a questão da culpabilidade. Tradicionalmente, não praticava crime aquele que sofria de delírio e que possuía distúrbios, mas, diante das monomanias, degenerações, atavismos e outras complexidades mentais, o médico se vê na legitimidade de questionar o funcionamento do direito de punir, quando aplicado a situações onde os motivos desaparecem e o fato parece sem explicação plausível, racional. ${ }^{4}$ Vê-se também perante o desafio de averiguar a responsabilidade ou não do agente, de evitar o erro de se condenar um louco ou de se inocentar um criminoso que pudesse estar tentando se passar por louco.

Por seu turno, a “interferência” do saber-poder médico e a "pretensão" de ampliar os casos de desculpabilização incomodaram muitos juristas. Questionável, por si só, a 
competência da Medicina e questionável também sua legitimidade para decidir o destino de alguém que está submetido à Justiça. Os conflitos de atribuição entre os médicos e os juristas foram, então, inevitáveis, quando os exames passaram a constituir um instrumento de poder sobre o destino das pessoas; e como instrumento de poder se tornaram alvo de disputa e de conflituosidade tanto internamente, pelas divergências teóricas entre os próprios médicos, como externamente, no embate com a polícia e com o judiciário.

Pondera Ferla (2005) que os principais “adversários” da produção médico-científica, em que o laudo se concretizava como diagnóstico da verdade, se personificavam no material policial produzido, muitas vezes por meio de tortura; nos veredictos leigos do júri; nas provas atécnicas, como a testemunhal.

De fato, além das veementes opiniões contrárias ao Tribunal do Júri, os cientistas da época também se voltaram contra os testemunhos, a ponto de propor a realização dos exames de sanidade mental também nas testemunhas, conforme propunham Ferreira Antunes e Juliano Moreira.

A crença na certeza da perícia motivou o projeto de estender os exames médicolegais para outros indivíduos relacionados ao processo, bem como instigou médicos influentes a propor a obrigatoriedade de alguns exames a todos os delinquentes e não só quando houvesse requisição judicial.

A medicalização do criminoso brasileiro eclodiu no fim do século XIX, portanto, por uma série de fatores presentes nesse momento histórico de profusão científica, que permitiria a "elevação" do país à categoria de nação civilizada. Seriam necessárias várias medidas não só no campo do Direito e da Política, mas também da Literatura, da Economia, da Filosofia e da Educação. ${ }^{5}$

Acontece que, enquanto na Europa, a Escola Positiva da Criminologia veio cem anos depois da conquista de direitos civis pelo reconhecimento das liberdades e igualdades, no Brasil, a reivindicação pela Escola Científica-Liberal veio simultânea às reivindicações pela efetivação das garantias básicas, como a liberdade de consciência. Não é de se estranhar, pois, que o primeiro Código Criminal da República, apesar de datar de 1890, tenha incorporado pouco da doutrina Positiva, sendo mais fiel à Escola Clássica. Era necessário, primeiro, implementar o novo Estado e, paulatinamente, aprender a lidar com a nova estrutura para, depois, avaliar a conveniência da adoção das teorias de Lombroso, Ferri e Garófalo, cuja resistência já era manifestada por muitos. Esse trio italiano, entretanto, teve a capacidade de estimular novas reflexões e de avançar na medicalização do criminoso, garantindo o espaço do saber médico no Judiciário.

\section{O CRIMINÓLOGO NINA RODRIGUES}

Um dos grandes responsáveis pela consolidação desse saber-poder no Brasil foi Raimundo Nina Rodrigues. O médico e professor era considerado por Lombroso o 
“Apóstolo da Antropologia Criminal no Novo-Mundo”. Uma de suas obras de maior relevância foi As raças humanas e a responsabilidade penal no Brazil, de 1894, cujo título já demonstra sua preocupação recorrente com as possíveis inter-relações entre características físico-raciais e criminalidade.

Com o mesmo modelo evolucionista, Nina Rodrigues parte do princípio de que foi com o aperfeiçoamento da série animal que se deu a crescente complicação do sistema nervoso, cuja composição histológica ou bioquímica da massa cerebral dependia de muitas décadas de adaptação e de transmissão hereditária por muitas gerações. Nisso se incluíam os graus sucessivos do desenvolvimento mental dos povos, os quais, dependendo de seu estágio evolutivo, não estariam aptos a receber, de uma hora para outra, a civilidade de uma cultura muito diferente. Assim como cada indivíduo tem seu ritmo de evolução, os povos têm seus graus de evolução mental, daí "a impossibilidade de supprimir a intervenção do tempo nas suas adaptações e a impossibilidade, portanto, de impor-se, de momento, a um povo, uma civilisação incompatível com o gráo de seu desenvolvimento intellectual” (Rodrigues, 1894).

Para exemplificar o atropelo do tempo e o insucesso de adaptação social, esse autor se refere aos aborígenes dizendo estarem eles incapacitados organicamente para atender ao que exigia a civilização. Tratava-se, portanto, de uma realidade material a que o estudo das "raças inferiores" poderia contribuir, fornecendo à ciência os casos em que as observações positivas constatariam tal incapacidade orgânica, cerebral, afastando as especulações metafísicas da filosofia espiritualista:

Applicado á genese das idéas do bem e do mal, do justo e do injusto, do direito e do dever - base moral e supposto fundamento do direito de punir da escola criminalista classica -, o methodo comparativo, que vimos operar tão grande revolução na psychologia, demonstra que, longe de uma procedencia sobrenatural ou supra-sensivel, essas idéas não são mais do que o resultado ideal da elaboração psychica por que passou o sentimento instinctivo de defeza fatal e mesmo inconsciente nas suas manifestações reflexas primordiais. A inneidade dellas, verificada pela analyse subjectiva nas raças superiores e que pareceu justificar a crença na sua proveniência extra-natural, se explica ao contrario muito naturalmente pela procedencia hereditaria, legado que foi de muitos seculos de repetição e aperfeiçoamento, o que acabou por identifical-as e tornal-as inherentes ao aperfeiçoamento psychico da humanidade (Rodrigues, 1894).

Argumentando a favor da relativização das ideias tidas como universais - do bem e do mal, do justo e do injusto - de acordo com o país e a raça, contrapõe-se ao ensino oficial e clássico do qual ainda estava impregnada a legislação brasileira. A antropologia, dizia Rodrigues, seria a ciência capaz de desmentir essa universalidade 
através da comparação entre os povos dos sentimentos de reprovação ou louvor, de criminalidade ou permissão, de punição ou de prêmio, presentes em uma mesma época ou os sentimentos que um mesmo povo teve ao longo de diversas épocas.

Assim é que a ideia de justiça, por exemplo, se apresenta hoje para nós diferentemente de como se apresentava em momentos mais remotos e também se apresentava hoje para nós diferentemente de como se apresenta ainda hoje para outros povos que tenham graus diferenciados de evolução mental. Disso dependeria um aperfeiçoamento social que paulatinamente, ao longo de gerações, vai inculcando no cérebro humano uma determinada noção compartilhada entre aqueles que se encontrem no mesmo nível evolutivo. O mesmo se daria com a noção de crime e de pena. Segundo Nina Rodrigues:

... para que se possa exigir de um povo que todos os seus representantes tenham o mesmo modo de sentir em relação ao crime, que formem todos da acção delictuosa e punivel o mesmo conceito, para que a pena, aferida pela imputabilidade, não se torne um absurdo, um contrasenso, indispensavel se faz que esse povo tenha chegado ao gráo de homogeneidade que Tarde, inspirando-se nas suas theorias sobre a imitação, descreveu magistralmente como o elemento social da identidade em que, em sua teoria, faz elle consistir o criterio da responsabilidade penal (Rodrigues, 1894).

Ao se contrapor à uniformidade universal da legislação, o autor defende um conjunto específico de leis para determinadas regiões. Um Código Penal nacional e isonômico ofenderia um postulado médico básico, o de que as pessoas são biologicamente distintas e, por isso, também o são os sistemas culturais.

As premissas do estudo de Nina Rodrigues (1894) foram resumidas por ele da seguinte forma: (1) a cada fase da evolução da humanidade, se comparam raças antropologicamente distintas, corresponde uma criminalidade própria, compatível com o grau do seu desenvolvimento intelectual e moral; (2) existe uma impossibilidade material, orgânica, de os representantes das fases inferiores da evolução social passarem bruscamente, em uma só geração, sem transição lenta e gradual, ao grau de cultura mental e social das fases superiores; (3) perante as conclusões tanto da sociologia como da psicologia moderna o postulado da vontade livre como base da responsabilidade penal só se pode discutir, sem flagrante absurdo, quando for aplicável a uma agremiação social muito homogênea, que esteja num mesmo grau de cultura mental média.

Ao considerar o acentuado desnível em que vivem as raças inferiores, o médico sustentou que a organização fisiopsicológica desses indivíduos não comporta uma mesma consciência do direito e do dever de que seriam possuidores os povos cultos em razão do acúmulo de aperfeiçoamento transmitido hereditariamente durante a 
sua passagem da selvageria ou da barbárie à civilização. Por isso, nada justifica responsabilizar os selvagens e os bárbaros pela falta dessa consciência, do mesmo modo que não justificaria punir os menores por não serem adultos ou os loucos por não serem sãos. Nina Rodrigues, nesse sentido, se mostra em sintonia com a teoria do atavismo empregada por Lombroso, não se fazendo de rogado ao declarar que constitui fonte dos atos violentos e antissociais a impulsividade primitiva típica das raças inferiores; típica, pois coerente com os atos reflexos e automáticos das espécies menos evoluídas. Ao contrário, quanto mais subirmos na escala evolutiva, mais se esperam ações refletidas, amparadas em arranjos psíquicos de ordem mais elevada.

Dentre os elementos antropológicos puros da população brasileira, o desafio residia na averiguação da responsabilidade criminal do negro (representado pelos povos africanos e pelos negros crioulos não mesclados) e do índio (ou raça vermelha representada pelo brasileiro guarani e por seus descendentes civilizados) incorporados à nossa sociedade. A raça branca (representada pelos brancos crioulos não mesclados e pelos europeus, ou de raça latina, principalmente os portugueses e os italianos, ou de raça germânica, os teuto-brasileiros do sul da República) era o exemplar dos povos superiores. Os mestiços, ${ }^{6}$ também, por carecerem de unidade antropológica, reforçavam a prova da necessidade de que a questão da responsabilidade fosse solucionada sempre no nível individual. Senão, vejamos, diante da perpetração de um crime por um negro ou por um índio excepcionalmente evoluído:

Para logo surgirá a duvida muito bem fundada, o problema imperioso de saber: se o conflito, que a imposição, mais ou menos violenta, de uma civilisação superior, creou entre os sentimentos moraes novos, superficiaes e ainda não completamente radicados de um lado, e os instinctos antigos, cimentados e estratificados pela herança de uma longa cadeia de antepassados, de outro lado, é ou não de ordem a perturbar tão profundamente o mecanismo da determinação voluntaria, de modo a dar ganho de causa e predominio ás impulsões instinctivas e indomaveis, - criminosas no novo meio -, mas completamente inimputaveis" (Rodrigues, 1894).

Se, à primeira vista, negros e índios merecem, por sua inferioridade a priori, uma responsabilidade atenuada, certo é que outros negros e índios em estado selvagem são totalmente irresponsáveis, segundo Nina Rodrigues. Quanto aos mestiços, dependendo do estágio em que o indivíduo se encontrasse na escala evolutiva - que vai do produto "inteiramente inaproveitável e degenerado" ao produto "válido e capaz de superior manifestação da atividade mental" - igual correspondência terá a responsabilidade moral e penal, desde a sua completa negação em um extremo, até a sua afirmação no lado oposto. A intuição, todavia, é que, por ser o mestiço um "híbrido social”, ele conta com um "defeito de organização", uma "insuficiência" ou 
“desarmonia do desenvolvimento fisiopsicológico”, devendo ser menos responsável do que os brancos civilizados. Às raças inferiores

... falta-lhes a consciencia plena do direito de propriedade. E a consciencia do direito é momento capital, elemento constitutivo da qualificação de criminalidade (Berner, Tobias Barreto).

Domina-os a impulsividade. E a impulsividade, - seja pathologica por destruição morbida do freio superior dos motivos psychicos de ordem mais elevada, das emoções nobres, seja congenital ou constitucional por falta ou por insufficiencia do desenvolvimento desse freio -, é sempre a mesma e tem o mesmo alcance. Em ambos os casos ella mantem dominada a livre determinação voluntaria e destroe pela base toda e qualquer responsabilidade que se funde na liberdade do querer" (Rodrigues, 1894).

Tendo a inferioridade de certas raças como forte convicção, Nina Rodrigues se entusiasmou com a história de Antônio Conselheiro. Apesar de defender a análise individualizada, o médico tomou todo o grupo de jagunços como objeto e generalizou o diagnóstico ao intitular o episódio "a loucura epidêmica de Canudos". Em primeiro plano, põe a "vesânia” que aflige a personagem principal e o meio propenso à sua proliferação: "é examinada por este prisma que a cristalização do delírio de Antonio Conselheiro no terceiro período da sua psychose progressiva reflete as condições sociologicas do meio em que se organizou" (Rodrigues, 1897). A saga de Antonio Maciel é, então, estudada com detalhes.

Sua história de missionário delirante pelos sertões da Bahia parece consubstanciar a fase megalomaníaca do final de sua vida, após alguns meses de propaganda religiosa no Ceará, de prisão por suspeição de crime com posterior absolvição, e de descontentamento com as mudanças políticas de secularização do fim da década de 1880. A instituição do governo Republicano provocou sua insubordinação ao governo civil e o reconhecimento deste governo pelo clero incitou a revolta contra os poderes eclesiásticos. A luta armada começou.

Quando Nina Rodrigues escreveu esse relato, o exército já se encontrava há três meses em Canudos sem conseguir dar cabo da revolta. Intrigava-lhe, portanto, como um louco como Conselheiro conseguira mobilizar tantas pessoas com sua palavra. A resposta, ele encontrou nas características raciais dos jagunços, o qual

... é um producto tão mestiço no physico que reproduz os caracteres anthropologicos combinados das raças de que provém, quanto hybrido nas suas manifestações sociaes que representam a fusão quasi inviavel de civilizações muito desiguaes (...) revelam-se inteiriços o carater indomavel 
do indio selvagem, o gosto pela vida errante e nomade, a resistencia aos soffrimentos physicos, á fome, á sede, ás intemperies, decidido pendor pelas aventuras da guerra cuja improvização elles descobrem no menor pretexto, sempre promptos e decididos para as razzias das villas e povoados, para as depredações á mão armada, para as correrias de todo o genero que os interesses do mando, as exigencias da politicagem e as ambições de aventureiros fazem succeder-se de continuo por toda a vasta estensão das zonas pouco habitadas do paiz (Rodrigues, 1897).

O ambiente era ideal para estimular os instintos guerreiros desses mestiços. Faziam o que determinavam suas peculiaridades atávicas sem possuírem a capacidade mental por desenvolvimento intelectual, ético e religioso insuficiente ou incompleto -, para compreender as mudanças políticas que sofisticaram a encarnação do poder na lei republicana. A dependência de uma voz de comando, da figura tradicional do monarca, foi, nas explicações de Nina Rodrigues, a origem da força sugestiva de Conselheiro.

Em outro trabalho, o autor, além de aprofundar o estudo sobre as "collectividades anormaes", examinou os casos de loucura a dois e, especialmente, o atentado da Praça Mauá. Aos 5 de novembro de 1897, Marcellino Bispo tentou assassinar o então presidente Prudente de Morais, a mando de Deocleciano Martyr. Nina Rodrigues estuda o perfil do executor e o classifica como um "regicida", pois

Aos regicidas pertence elle [Marcellino] pela idade, pois contava apenas 22 annos e os regicidas raramente têm mais de 30, oscillando de ordinario entre 20 e 25 . Entre os regicidas celebres tinham (...) Guiteau, 40, etc. E esta precocidade é a melhor prova de que as solicitações psychicas que conduzem ao regicidio se encontram especialmente nos jovens, exactamente como as demais manifestações da degenerescencia. Pelos laços hereditarios, Bispo pertence tambem aos regicidas. É elle mestiço em sangue muito proximo dos indios brasileiros, pois seus pais descendiam de indios do extincto aldeiamento do Urúcú, em Alagôas. Já desta circumstancia se pode induzir o grau da sua impulsividade hereditaria. Mas a autoridade que, por ordem do governo, abriu inquerito sobre a familia de Bispo, informa que si os pais do assassino eram honestos, pacificos e laboriosos, 'houve outros parentes do criminoso, caboclos perversos e assassinos e dentre estes um que ha tempos assassinou o proprio irmão'. Aos regicidas pertence principalmente Marcellino Bispo por sua natureza, pois como todos os regicidas é evidentemente um degenerado (Rodrigues, 1939).

Esse regicida, que possuía inteligência "acanhada” e instrução "rudimentar”, deixava morbidamente se sugestionar, e seus impulsos naturalmente selvagens e violentos, 
eram perfeitos para transformá-lo em prisioneiro moral de quem o explorasse nessas tendências inatas. Nisso residia o fundamento do crime a dois e não muito longe estava o crime das multidões.

Voltando, assim, às coletividades anormais e ao livro que recebeu esse título, Nina Rodrigues complementou as anotações sobre Canudos. Seguindo a crença nas explicações comportamentais por meio da conformação do cérebro, ele acrescentou às conclusões anteriores sobre os jagunços o estado de exaltação passional coletiva em que se encontrava aquela multidão, desaparecendo "o controle da vida cerebral, e com elle, a personalidade consciente e o discernimento" (Rodrigues, 1939). Nesse sentido, a sugestão de Antônio Conselheiro não teria provocado simplesmente uma adesão consciente, mas sim "um estado delirante collectivo, de carater politico-religioso, dotado de uma tal intensidade que poude impellir os sectarios a todos os sacrificios. Foi um verdadeiro estado de multidão vesanico que se formou nesta seita de predispostos, de desequilibrados e loucos" (Rodrigues, 1939).

A excitação causada por Conselheiro se faria cessar por ele próprio ou com sua morte, o que acabou por acontecer em 1897. A cabeça foi separada do corpo e seu crânio foi oferecido a Nina Rodrigues. Nos parâmetros das pesquisas craniométricas, registrou-se:

... nenhuma anomalia que denunciasse traços de degenerescencia: é um craneo de mestiço onde se associam caracteres anthropogicos de raças differentes. Só relataremos aqui, pois, as indicações mais importantes. É um craneo dolichocephalo e mesorrhyno, quasi sem dentes, e com notavel atrophia das arcadas alveolares. Tem uma capacidade de 1670 cc. (...) É pois um craneo normal. Esta conclusão, que está de accordo com as informações recolhidas sobre a historia do alienado, confirma o diagnostico de delirio chronico de evolução systematica” (Rodrigues, 1939).

Por mais que Conselheiro fosse o comandante, não seria afastada, classicamente, a responsabilidade dos jagunços. Nossa legislação adotava o princípio do livre-arbítrio, logo os mestiços maiores e não doentes mentais seriam considerados imputáveis. As concepções de Nina Rodrigues, todavia - amparadas nas teorias do atavismo, da hereditariedade, da degenerescência, da inferioridade, enfim, na escola italiana de Lombroso -, firmavam uma nova doutrina e intentavam transformações nas instituições penais que levassem em consideração a ausência ou diminuição da culpabilidade de determinados indivíduos por força de sua raça, de sua mestiçagem não evoluída ou de seu "estado de multidão", como no exemplo de Canudos.

No Brasil, a teoria da degenerescência se destinou fortemente aos índios, aos negros e aos mestiços, na tentativa da explicação da inferioridade e suas consequentes 
manifestações, adaptando o princípio da igualdade para a realidade biológica: é preciso tratar desigualmente os desiguais (Alvarez, 2002).

Como podemos perceber com Nina Rodrigues, o contexto sociopolítico de fins do século XIX e início do XX favoreceu a consolidação da Antropologia [criminal] brasileira e sua atualização pelas mãos de Afranio Peixoto, Juliano Moreira, Arthur Ramos e outros, bem como a adoção de medidas públicas que consideravam as teses raciais em voga no pensamento social leigo e culto.

É impossível, portanto, falar do Brasil daquela época e não fazer referências ao tema racial.

\section{CONCluSÃo}

As expectativas quanto aos resultados que as pesquisas da Antropologia Criminal poderiam fornecer cruzaram continentes, oceanos e desembarcaram no Brasil. O papel que a medicina desempenhou no estudo da Criminologia científica, fortemente, no final do século XIX, impactou a literatura médico-jurídica brasileira e, aqui, fez escolas. Nomes como Raimundo Nina Rodrigues, Teixeira Brandão, Heitor Carrilho, Juliano Moreira, aplicavam suas premissas no campo criminológico, e renomados juristas e advogados também se deixaram seduzir por tais ideias. Entre eles, a título de exemplificação, João Vieira de Araújo, Augusto Olympio Viveiros de Castro, Cândido Mota, Esmeraldino Olympio Torres Bandeira, Antônio Moniz Sodré de Aragão e Pedro Lessa (Tórtima, 2002).

No Brasil, assim, também presenciamos a proximidade entre a Medicina e o Poder Judiciário, onde médicos reclamam o posto de peritos, cientistas imparciais não subordinados ao chefe de polícia e não desacreditados em sua isenção e competência. Na visão médica, o homem do direito era como um "assessor que colocaria sob a forma da lei o que o perito médico já diagnosticara e com o tempo trataria de sanar” (Schwarcz, 2008). Na visão jurídica, a questão se inverte, pois o homem da medicina era como "um técnico que auxiliaria no bom desempenho desses profissionais das leis” (Schwarcz, 2008).

Vê-se claramente um campo de disputas entre médicos e juristas que, todavia, mais se complementam no projeto de construção da nação do que se excluem. A “dialética” de convergência e divergência entre esses saberes aproximou-os em certos pontos e distanciou-os em outros, contudo, isso só revela um fluxo e contrafluxo normal no plano intelectual, registrado na história da intelectualidade brasileira.

Considerando que a racionalidade dos doutores poderia estar atrelada a uma mentalidade elitista, a uma opção política do tipo monarquia versus república ou escravidão versus abolicionismo, não se pode mesmo descartar a hipótese de essa construção teórica do século XIX ter referendado uma dominação social e uma 
garantia de ordem higienista que levava para fora da normalidade os mestiços, os capoeiras, os degenerados, os vadios, os inertes, os malandros e os criminosos.

$\mathrm{Na}$ época não havia a especificidade de uma intelectualidade médica voltada para a adequação de um programa de inclusão do Brasil no mundo "evoluído" com o perfil de uma população miscigenada e tropical. Nesse ambiente, fica claro que negros ocupavam um espaço de inferioridade, os porões das classes sociais. Muitas vezes ainda vistos como "coisa", serviam a seus senhores na medida das necessidades destes.

A partir da década de 1870, todavia, o cenário começou a mudar. Os contextos externo e interno, bem como o fortalecimento do movimento abolicionista, favorecerem o surgimento de novas reivindicações e de novas orientações políticas, literárias, artísticas, econômicas, etc.

: ARTIGO APROVADO (10/10/2010) : RECEBIDO EM 10/04/2010

\section{NOTAS}

1 Sugerem-se leituras da tradição foucaultiana de abordagem arqueológica e genealógica nas ciências humanas. Ver, por exemplo, Michel Foucault, As palavras e as coisas: uma arqueologia das ciências humanas (4. ed., Rio de Janeiro: Martins Fontes, 1987).

2 Schwarcz compartilha esse entendimento, mencionando a Lei do Ventre Livre, de 1871, o fortalecimento de centros de ensino que ocorreu naquela década, além de representar um marco na história das ideias brasileiras, pois sintetiza o "momento de entrada de todo um novo ideário positivo-evolucionista em que os modelos raciais de análise cumprem um papel fundamental" (2008, p.14).

3 Barros reduz o termo "Positivismo" à doutrina de Comte, mas concorda que, em termos mais gerais, poderíamos substituir "cientificismo" por aquele.

4 Trata-se de casos como o de Henriette Cornier e Pierre Rivière, estudados por Foucault (2002). Para Robert Castel: "Essas exceções literalmente transtornantes questionam o direito de punir ao nível de seu funcionamento. Atos tão deslocados que não podem mais ser recodificados em termos de motivos. Eles desconcertam toda e qualquer justificativa racional da sanção, pois não podem ser referidos a nenhum cálculo. Que o aparelho da gestão da loucura o assuma, portanto" (1978, p.169).

5 Para Barros "é preciso substituir o romantismo pelo naturalismo, em literatura; o direito natural pelo direito positivo, na jurisprudência; o espiritualismo pelo monismo, positivista ou materialista, em filosofia; a monarquia pela república, em política; o privilégio pela livre concorrência, em economia, em educação; é preciso libertar a consciência do artificialismo das imposições constitucionais, para submetê-la apenas ao seu determinismo natural e às legítimas injunções coletivas; é preciso tornar livre o trabalho, rever a situação da mulher, reexaminar a concepção do Estado" (1986, p.172).

6 Segundo Nina Rodrigues "O conflicto, - que se estabelece no seio do organismo social pela tendencia a fazer, á força, iguaes perante a lei e seus effeitos, raças realmente tão distinctas e desiguaes -, tem o seu simile e se deve realisar 
no seio do organismo individual, nos casos de mestiçamento, que combina e funde de momento em um mesmo individuo qualidades physicas, physicologicas e psychicas, não só distinctas, mas ainda de valor muito differente no ponto de vista do conceito evolutivo do aperfeiçoamento humano. É verdade biologica bem conhecida que nos cruzamentos de especies differentes o exito é tanto menos favoravel quanto mais afastadas na hierarquia zoologica estão entre si as especies que se cruzam" (1986, p. 91).

\section{REFERÊNCIAS BIBLIOGRÁFICAS}

ALVAREZ, Marcos César. A criminologia no Brasil ou como tratar desigualmente os desiguais. DADOS - Revista de Ciências Sociais, Rio de Janeiro, v. 45, n. 4, p. 677-704, 2002.

BARROS, Roque Spencer M. de. A ilustração brasileira e a idéia de universidade. São Paulo: Convívio; 1986. p.7, 109.

CASTEL, Robert. A ordem psiquiátrica: a idade de ouro do alienismo. Rio de Janeiro: Graal, 1978.

CORRÊA, Mariza. As ilusões da liberdade: a escola Nina Rodrigues e a antropologia no Brasil. 2. ed. rev. Bragança

Paulista: Universidade de São Francisco, 2001.

DARMON, Pierre. Médicos e assassinos na Belle Époque. Rio de Janeiro: Paz e Terra, 1991.

FERLA, Luis Antonio C. Feios, sujos e malvados sob medida: do crime ao trabalho, a utopia médica do biodeterminismo em São Paulo (1920-1945) [Tese]. Pós-Graduação em História Econômica da Faculdade de Filosofia, Letra e Ciências Humanas da Universidade de São Paulo, São Paulo, 2005, p.169

FOUCAULT, Michel. Os anormais: curso no Collége de France (1974-1975). São Paulo: Martins Fontes, 2002.

GOFFMAN, Erving. Manicômios, prisões e conventos. 8. ed. São Paulo: Perspectiva, 2008.

ILLICH, Ivan. A expropriação da saúde: Nêmesis da medicina. 4. ed. São Paulo: Nova Fronteira, 1975.

RODRIGUES, Raimundo Nina. A loucura epidemica de Canudos: Antonio Conselheiro e os jagunços. Revista Brazileira, Rio de Janeiro, , p. 4, 11,12, 1897. As collectividades anormaes. Rio de Janeiro: Civilização Brasileira, 1939, p. 89, 130, 133, 173, 173.

104-105.

. As raças humanas e a responsabilidade penal no Brazil. Bahia: Imprensa Popular, 1894, p. 3, 8, 16, 19, 84-85,

ROSE, Nikolas. Beyond Medicalisation. Lancet, n. 369, p. 700-703, 2007.

ROSENBERG, Charles E. Contested Boundaries: Psuchiatry, Disease, and Diagnosis. Perspective in Biology and Medicine, v. 49, n. 3, p. 407-424, summer 2006.

ROUSSEAU, G. S. Para uma semiótica do nervo: a história social da linguagem em novo tom. In: BURKE, Peter; PORTER, Roy. (Orgs.) Linguagem, indivíduo e sociedade. A história social da linguagem. São Paulo: XXXXX, 1993.

SCHWARCZ, Lilia M. O espetáculo das raças: cientistas, instituições e questão racial no brasil - 1870-1930. São Paulo: Companhia das Letras, 2008.

SERPA JR., Octávio. Mal-estar na natureza: estudo crítico sobre o reducionismo biológico em psiquiatria. Belo Horizonte: Te Cora Ed., 1998.

TÓRTIMA, Pedro. Crime e castigo para além do Equador. Belo Horizonte: Inédita, 2002.

\section{Cristiane Brandão Augusto}

Av Presidente Wilson, 118

Centro - 20030-020

Rio de Janeiro - RJ - Brasil

pedipelaig.com.br
Doutora em CIÊnCIAS Humanas E SaÚde PElo Instituto dE MEdicina Social da UERJ

Mestra EM CIÊNCIAS JURÍDICO-CRIMINAIS PELA FACuldade de DiReito dA Universidade dE CoImbra

Graduada EM Direito PELA PUC/RJ

Professora de Direito PENAL dA UCAM,

DO IBMEC E DA EMERJ 
236 : NINA RODRIGUES E A PATOLOGIZAÇÃO DO CRIME NO BRASIL

\section{Francisco Ortega}

Rua São Francisco Xavier, 524 - $7^{\circ}$ andar - Bloco D Maracanã - 20559-900 Rio de Janeiro - RJ - Brasil fjortegalauol.com.br
Doutor EM Filosofia PeLA Universidade de BieleFELd Graduado em Filosofia pela Universidade COMPLUTENSE DE MADRID 